\title{
DESIGN AND DEVELOPMENT OF TACTICAL MONITORING FORCE USING ONLINE BASED TELEMETRY SYSTEMS FOR MATAN BATALYON COMMANDO PASKHAS TEAM
}

\author{
Zainal Syahlan, Ahmadi, Suprayitno, Robert Radiyanto \\ D-3 Informatics Engineering, \\ Indonesian Naval Technology College, STTAL Surabaya Indonesia
}

\begin{abstract}
The operational equipment of the Security and Rescue Team (Matan) of the Paskhas Command Battalion called the Integrated Personal Protection (IPP Set) is currently incomplete because monitoring of the implementation of the Matan Team's activities is limited to reports through radio / HT communication tools, so that in decision making actions by the Operations Commander Puskodalops is not optimal and accurate according to the conditions in the field. Therefore we need a system that can monitor the movements of the Matan Team that can monitor the position and visual forces in real time. This monitoring system using radio telemetry can transmit data in the form of GPS coordinates displayed by Google Map as well as visual image data recorded by FPV cameras in realtime using the 3DR telemetry transmission system $433 \mathrm{Mhz}$ and VTX $5.8 \mathrm{Ghz}$ mounted on a tactical helmet and received by ground station receiver antennas at Puskodalops, so that the position of the matan team personnel can be monitored and conditions in the field can be monitored in realtime so that the Operations Commander can make decisions more quickly, precisely and accurately according to field conditions.
\end{abstract}

Keywords : Telemetry, Security and Rescue Team (Matan),

\section{INTRODUCTION}

\section{$1.1 \quad$ Background}

The Special Forces Corps, abbreviated as Korpaskhas, is a special force owned by the Indonesian Air Force. Korpaskhas is a land combat unit that has the ability to 3 dimensions, namely land, sea and air. Every Korpaskhas soldier is required to have at least the qualifications of the Commands to be able to carry out their duties professionally and supplemented with special abilities in the area according to the specialization of their task units.

The Korpaskhas as the Main Command of Guidance is tasked with fostering the strength and capability of the Paskhas unit as an air force force to be ready for operations in carrying out the seizure of strategic targets and defense of the Indonesian Air Force, Air Defense, Special Operations and Typical air dimensions in military operations in accordance with the TNI Commander's policy.
The Paskhas Command Battalion Matan Team which is part of the Korpaskhas has special tasks in day-to-day operations, including VIP / VVIP security operations in the Security One Ring, therefore personnel are needed by using special equipment called the Integrated Personnel Protection Set (IPP set). One part of the IPP set is a tactical helmet, in addition to being a head protector, this helmet also functions as a communication tool in the form of headphones connected to HT Radio which functions as a communication tool between personnel and personnel with tactical posts.

At present the tactical helmet used by the Matan Team is only equipped with a headphone and $\mathrm{HT}$ radio, so reporting every activity from the Matan Team personnel in the field to the Operations Control Command Center (Puskodalops) which is outside the operating area can only be heard with sound media and cannot yet be heard displayed visually and Puskodalops had difficulty knowing the exact location of personnel in the field. This will certainly make it very difficult for the Commander or Chief in monitoring the 
movement and in making a decision on the actions of a fast and appropriate operation and in evaluating the operational activities of the Matan Team.

From the description of the problem above according to the author to be able to maximize reporting, coordination and monitoring of troop movements in the field, then the writer has an idea or an idea to make a "DESIGN AND DEVELOPMENT OF TITICAL MONITORING HELMET SYSTEM FORCES WITH THE TELEMETRY SYSTEM BASED ONLINE FOR THE DEATH BATALYON KOMANDO COMANDO SYSTEM" able to send data in the form of GPS coordinates and video display in realtime so as to be able to monitor any troop movements in the field.

\subsection{Problem Formulation}

Based on the background description above, the problem can be formulated, namely how to design a tactical helmet monitoring system for troops using an online-based telemetry system for the Paskhas Command Battalion Matan Team that can display location and visual data that can be monitored by the Tactical Command Post and Headquarters Puskodalops in realtime?

\subsection{Research Objectives}

The purpose of this study is to design a tactical helmet monitoring system for troops using an online-based telemetry system for the Paskhas Command Battalion Matan Team that can display location and visual data that can be monitored by the Tactical Command Post and the Puskodalops headquarters in real time.

\subsection{Research Benefits} follows:

The benefits of this research are as

a. For Matan Team Personnel, it is easy to find out the position of these personnel with the help of GPS connected to the Google Map displayed on the Micro OLED Display screen mounted on the tactical helmet visor glass.

b. For the Tactical Command Post, it is easier to supervise and control the movements of the Matan Team in the field because they can see visually and realtime events that occur in the field.

c. For the Commander / Leader, Facilitate making decisions in carrying out the security operations.

\section{LITERATURE REVIEW}

\subsection{Information Systems}

Information system, according to (Rommey, 1997) is a system that is organized by collecting, entering, processing, and storing data which is then organized to store, manage, control, report information in a certain way to achieve the goals set.

The implementation of special information systems for national defense becomes something that needs to be developed in the implementation of accountable national defense. This information system is a single entity that cannot stand alone and must be integrated with others so that it will be easy to update all changes and developments that occur both from internal and external of the defense information system. The TNI information system as part of the national defense information system was developed and developed by the TNI Headquarters under the Supervision of the Ministry of Defense to lead to a design based system, which is to build and enrich an information technology based system. This system also provides data and information services in order to support the implementation of national defense which includes internal services to achieve the goals of bureaucratic reform within the Ministry of Defense and the TNI (Dr.Ir Supartono MM, 2014).

\subsection{Telemetry Radio System}

Telemetry is a measurement technology that is done remotely then reports information data to the system operator. The origin of the word telemetry from the Greek language is tele means distance and metron means measurement. In terms of terms it can be interpreted as an engineering field by using instruments to measure heat, radiation, speed and sending measurement results in the form of data to a receiver a distance away from the observer's ground station.

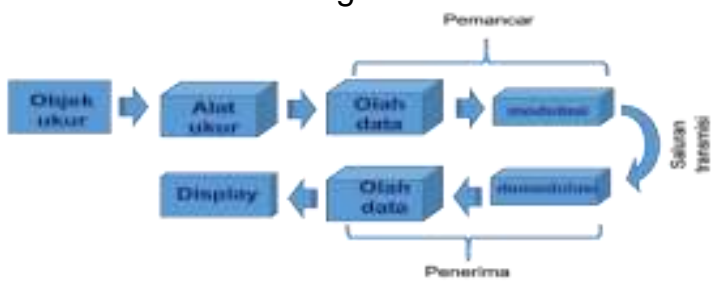

Figure 1 Telemetry system

Data communication is part of the communication system concerned with the use of transmissions for the transfer of data and information using computers and other devices with digital form and then sent using data 
communication media. Data can mean information that is presented with digital cues.

\section{$2.3 \quad$ Internet}

The internet began as a network, called the ARPANET. is the result of trials / experiments of the American government in the form of a packet-switched networking. In the early 1980 s, the ARPANET was divided into 2 network groups, the ARPANET itself and the Milnet (secret military network). At the beginning of its construction, access to ARPANET was primarily for the military, defense contractors, and certain universities. Cooperative, decentralized networks such as UUCP, UNIX communication networks, and USENET (User's Network) were established in 1970, initially serving communication for academics and developing in the service of commercial organizations. In the early 1980s, networks such as the Computer Science Network (CSNET) and BITNET, provided a wide spread network for universities and research. This network is not a part of the internet, but is a special connection created to seek the exchange and exchange of information between the two networks.



Figure 2 Global Internet Network

\section{RESEARCH METHOD}

\subsection{Research Design}

In this design we use the System Development Life Cycle (SDLC) research design. SDLC is the stage for analyzing and building system designs using cycles that are specific to user activities.

In developing the system using SDLC there are several models used, one of which is the waterfall model. Waterfall is a process model in developing software that has systematic and sequential properties in building a software. The stages in this model include analysis, design, coding, testing and maintenance.

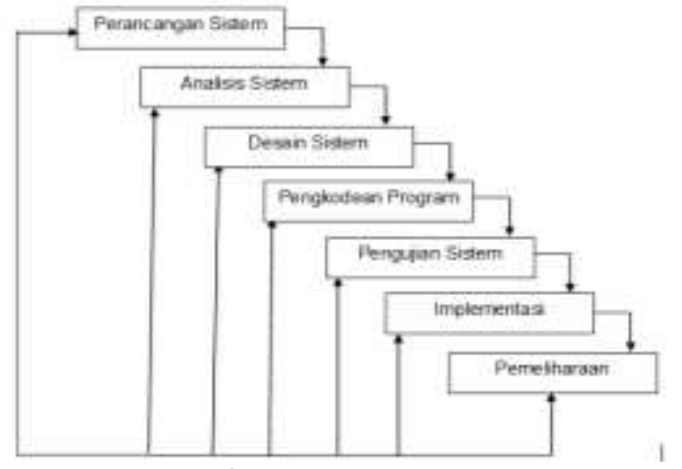

Figure 3 Waterfall Model

\subsection{Prosedur Penelitian}

The research procedure is a sequence of steps as well as an explanation of a research process that will be carried out, starting from the design work system diagram to the input and output systems that are expected or to be produced.

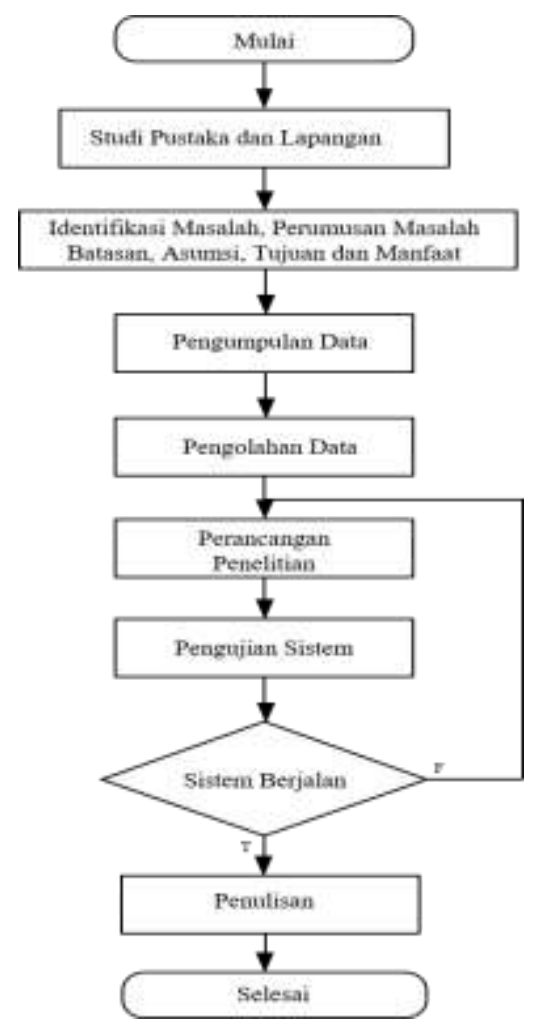

Figure 4 Flowcart research procedure

\subsection{Time and Place}

The time for the final assignment research is in August 2019 while the place for conducting the research is in the 463th Battalion of Pakhas, Madiun and STTAL Surabaya. 


\subsection{Tools and Materials}

In carrying out this research, several tools and materials are needed to facilitate the design and trial of research. The tools and materials needed in conducting the research include:
a. Tactical Helmet.
b. Arduino Nano.
c. Camera FPV 700 TVL V / A.
d. GPS module.
e. 3DR Radio Telemetry.
f. Video Transmitter and Receiver.
g. FPV Ort Pagoda antenna.
h. PC / Laptop.
i. Micro OLED.
j. Battery.
k. Mysql Database Software.
I. Visual Comunity 2017 Software.

\subsection{Research Design}

The system design will be carried out after an analysis of the system, which in the design of this system can provide an overview of the system to be made. The general description of the system to be made is as follows:

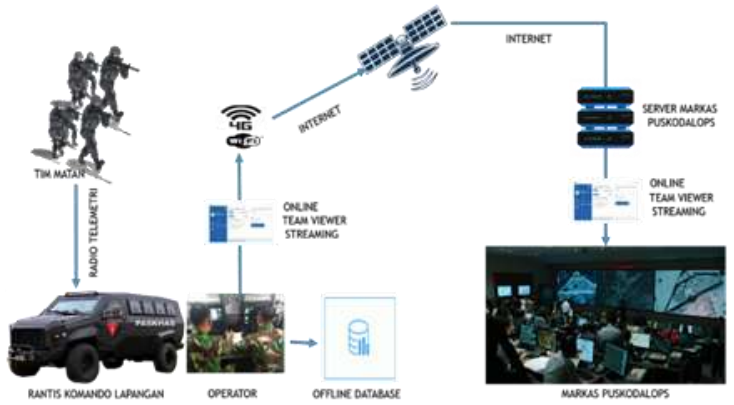

Figure 5 Overview

\subsection{System Design}

According to (John Burch and Garry Grudnitski, 1986), "system design can be determined as drawing and sketching or arranging separate elements into one, all working together." From this definition it can be concluded that the system design is the stage of drawing, planning and making to unite several separate elements in a unified system to clarify the system.

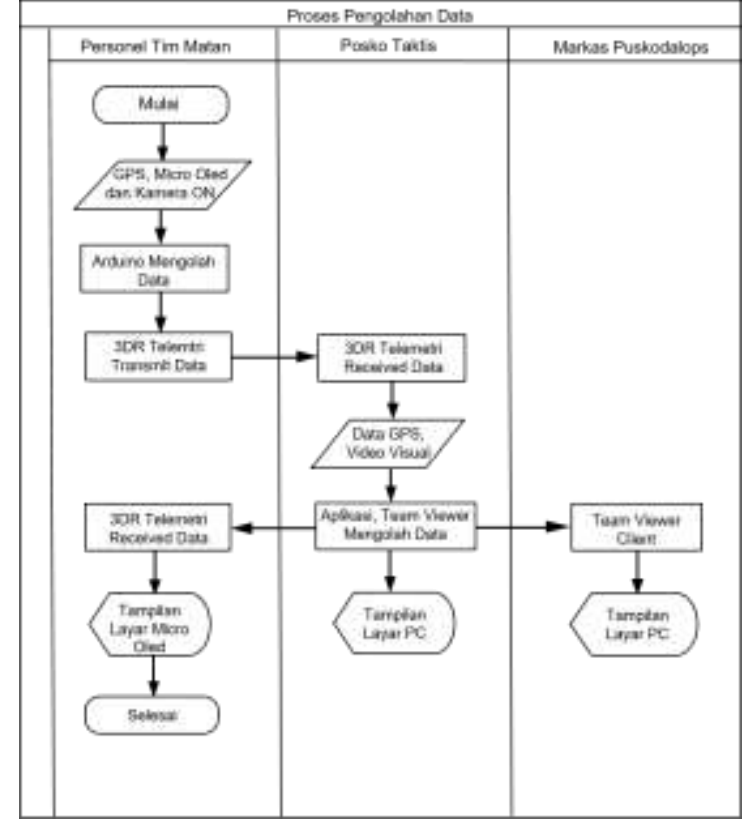

Figure 6 System Flow Document

Figure 6 is a Document Flow chart showing the flow of documents between parts in the system logically. Can describe each part of the organization involved in processing documents in the processes undertaken.

Context diagram is a process that describes the scope of the system. This context diagram is part of the highest level DFD (Data Flow Diagram) which describes all the inputs to the system or the output of the system or a picture of all systems.

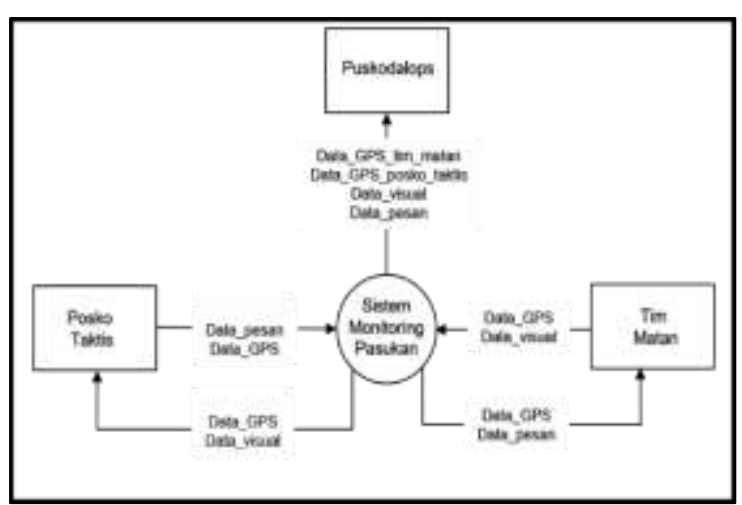

Figure 7 Context Diagram

DFD (Data Flow Diagram) is a model or process of logical data designed to describe the origin and destination data coming out of the system, where the data is stored, data processing and interactions between the data stored and the processes carried out on the data. 




Figure 8 DFD level 1

\section{7 Data Collection}

The methods used to collect data in this research system are:

a. Observation method is a method of data collection which is done by direct observation of data relating to this research, in this design the author's plan will observe the Pam VVIP / VIP activities conducted by the Battalion Commander Team 463 Paskhas Battalion in the period August 2019 as well as making comparisons in the use of some of the tools used by the Matan Team including GPS, Compass, Maps and Communication Tools, so that the writer gets the information needed to complete the data of the device design.

b. Interview Method is a method of interview or question and answer that is directly carried out to sources relating to the design of the tool where the information obtained can strengthen the data needed, the author plans to conduct interviews with the Battalion Commander, Team Matan Commander and several members of the Matan Battalion Team Command 463 Paskhas in August 2019.

c. Literature study method is a method of data collection which is done by finding references from books, journals and internet media related to this research, in this design the author plans to visit the STTAL library and look for several books in Gramedia Stores and use the internet media to search for journals. -journals related to the design of the tool.

\subsection{Data Processing}

Data processing is the processing stage of data that has been successfully collected for further processing to be presented and applied in a system that is being designed by the author. The design of this system will be tested on the 463 Paskhas Command Battalion Matan Team using a local network system. The main purpose of this test is to find out whether the tools that have been made can meet the needs of the Matan Team as a user and whether the tools can already provide the results that are expected. The trial is done by evaluating and testing the functions contained in the system. When errors are found, repairs will be made and then re-evaluated or tested until the application does not experience errors.

\section{ANALYSIS AND DISCUSSION}

\subsection{Design.}

Design is a process carried out on a project that will be done, starting from the research design, to the finished results that will be functioned. In principle, good design and systematic can provide convenience in the manufacturing process to become an application system that really functions as it should. In designing the tactical helmet monitoring system the troops use online telemetry radio for the Pasatan National Command Battalion Matan team consists of several designs, namely the design of hardware and software used to build applications.

\subsubsection{Hardware Design}

Hardware or also referred to as hardware is a device that can be touched and can be seen in plain or tangible form. This hardware trimmer functions to support the work of the system to be created. In designing hardware, namely by determining the form of design of tools that are made so that it can support the success of the system's work. And what electronic devices are used in the circuit that produces a system.

\section{a. 3DR Telemetry Transmitter Unit Circuit Design.}

In this trasmitter unit, there are several main tools that are part of the system design that will be built, among others, FPV and GPS cameras as data input devices and Micro OLED as data output devices, the three devices are assembled with rduino microcontrollers, 3DR telemetry, AKK FX and the battery thus becomes a series of interconnected systems that will produce an electronic circuit in this troop monitoring system. 


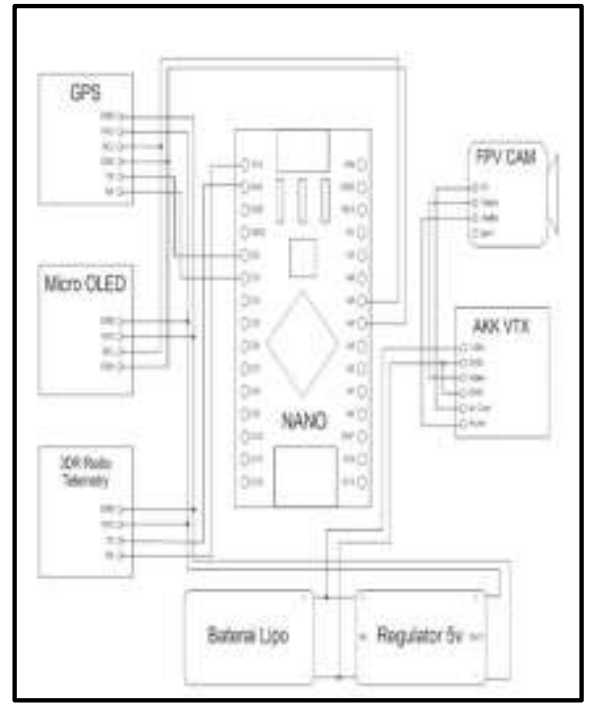

Figure 9 Transmitter unit circuit design

b. Design of Ground Station Receiver Unit Circuits.

At the ground station this unit consists of 2 parts of the receiving antenna, namely the 3DR Telemetry ROTG section which is in charge of receiving analog signals transmitted by 3DR RTK antennas in the form of GPS data and short message data, then the next part is the VTX antenna which is tasked with receiving digital signals in the form audio and video data transmitted by the AKK FX antenna on the transmitter unit.



Figure 10 Ground station unit circuit design

\subsubsection{Software Design}

Software or software can be called a special term for data that is formatted and stored digitally, including computer programs, documentation, and various information that can be read or written by a computer. In designing software for Arduino Nano is to use the $\mathrm{C}$ programming language which is open source software. The advantage of open source software is that the command to run a sensor or module can be done by anyone and according to the wishes of the program maker. Then the program that has been created is uploaded to the microcontroller. Program commands will be stored in EEPROM or called Electrically Erasable Read Only Memory which is storage memory that stores configuration data that is maintained or not erased when the power source is disconnected and then revived.

\section{a. Log In Page Design}

The Log In design is the page that first appears when the application is run. The Log In page functions as a gateway to the troop monitoring application system. In the design of this page, there are two inputs, namely username and password.



Figure 11 Log In page design

b. Home Page Design

The home page design is the initial page of the application that can be accessed first after the operator has successfully entered the application. This page contains some general information about the Korpaskhas, Team Matan and an overview of the application of the troop monitoring system.



Figure 12 Home page design

\section{c. Main Page Design}

The design of the main page will display the geographic information of the troop coordinates using googlemap as well as the video display recorded by FPV cameras in realtime and the message sending window that can be read by personnel who use this tool which will be displayed on the Micro OLED screen mounted on a tactical helmet. 


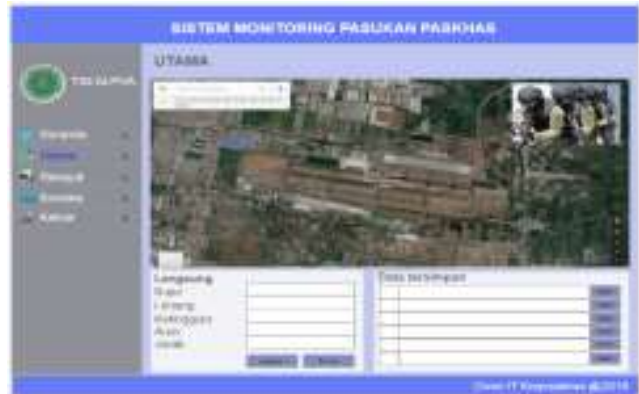

Figure 13 Main page design

d. History Page Design The history page design contains stored data such as message data, coordinate data and video chapture recording data. So hopefully all activities using this application can be recorded properly and can be seen or played at a later date.

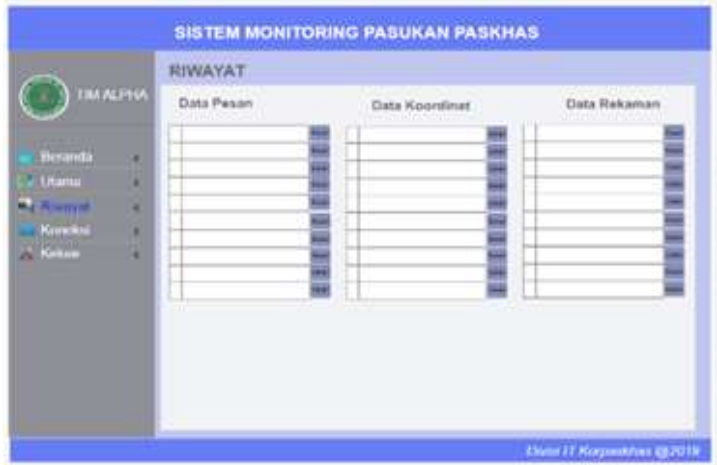

Figure 14 Design history page

e. Connection Page Design

The connection page design contains the telemetry wave connection information of the transmitter unit mounted on a tactical helmet with a ground station unit connected to a laptop / PC, it is hoped that with this page the operator can know the connection of this troop monitoring device.

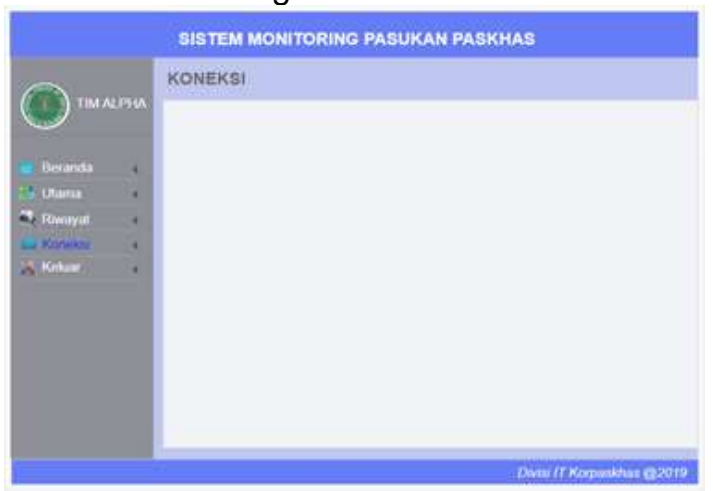

Figure 15 Connection page design

\section{2}

\section{Implementation}

Implementation as an application or the result of a design derived from an idea is then carried out a study. Implementation or application of the results of the above design namely the implementation of hardware and software implementation where this implementation produces a monitoring system that can be used properly by the Matan Team.

\subsubsection{Hardware Implementation}

Hardware is the physical components of the equipment needed and assembled to form a computer system. The hardware used in the tactical helmet design and monitoring system of troops using online-based radio telemetry for the Pasatan National Command Battalion Matan team are:

\section{a. 3DR Telemetry Transmitter Unit}

In the hardware implementation, the transmitter unit will be attached to the tactical helmet, by attaching to the back of the helmet in the form of a series of arduino and transmitter antennas and batteries, then on the upper left a FPV camera is installed which is tasked to record images and Micro OLED units on the lower left part of the tactical helmet that is parallel to the user's eye helmet.

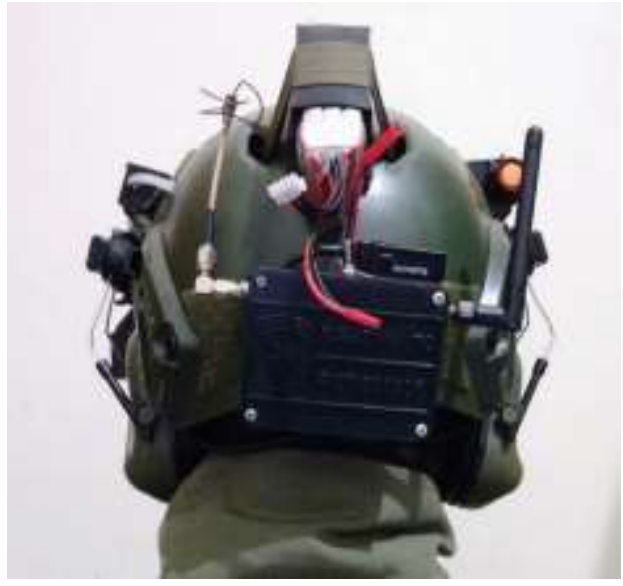

Gambar 16 Transmitter unit

b. Ground Station Receiver Unit

In this section, the ROTG antenna unit consisting of Pach antenna and Clover antenna is arranged into one part with the aim that the Pach antenna can direct the wave signal to one main point so that the signal can be received strongly while the Clover antenna is assigned to receive signals from various directions according to the radius of ability antenna. Both of these antennas 
are in charge of receiving audio video signals emitted by AKK VTX.

Whereas the 3DR Telemetry antenna is in charge of receiving signals containing GPS data and also that will transmit data short messages sent from the operator at the tactical command post to the Matan Team personnel who can be read on the Micro OLED display on the tactical helmet.

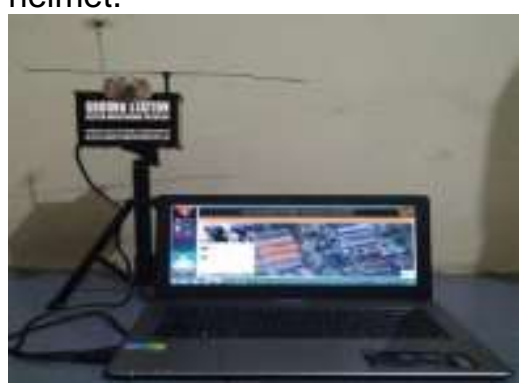

Gambar 17 Ground Station unit

\subsubsection{Software Implementation}

Software is an integral part of hardware. understanding software in general can be interpreted as a collection of electronic data stored and regulated by a computer in the form of programs or instructions to execute and execute a command. in the implementation of the tactical helmet design and monitoring system for troops using the online-based telemetry radio for the Pasatan National Command Battalion Matan team the software used can be seen in the following table:

Tabel 1 Software yang digunakan

\begin{tabular}{|c|l|l|l|l|}
\hline $\begin{array}{c}\mathrm{N} \\
0\end{array}$ & \multicolumn{1}{|c|}{ Nama } & Nama & Ket \\
\hline 1 & & Sistem & - Window & \\
& Operasi & s.1 & \\
\hline 2 & & Basis Data & - MySql & \\
\hline 3 & & Perangkat & - Visual & - C\# \\
& lunak & Studio & - C \\
& Pemrograma & 2017 & - Pytho \\
& n & $-\begin{array}{l}\text { Arduino } \\
\text { IDE }\end{array}$ & \\
& & - Mission \\
& & Planner & \\
\hline 4 & & Protokol & - I2C & \\
& & - UART & \\
& & - Serial & \\
& & USB & \\
\hline
\end{tabular}

a. Halaman Log In

The Log In page is used by the Operator to access the application program. When this troop monitoring application is opened, the first view that appears is the Log In view that will ask the application logger to enter a username and password as a condition of accessing the troop monitoring system.

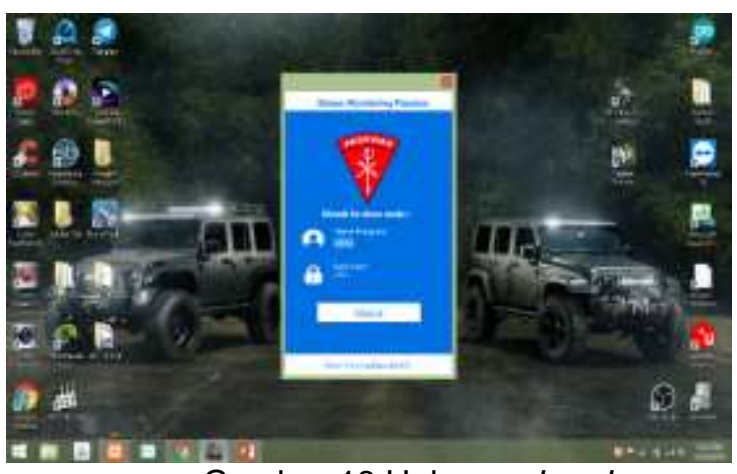

Gambar 18 Halaman Log In

b. Home page

The Home page on this troop monitoring application contains general information about the Korpaskhas, the Matan Team and the scheme of the work description of the troop monitoring application using this radio telemetry along with some pictures of the Matan Team activities.

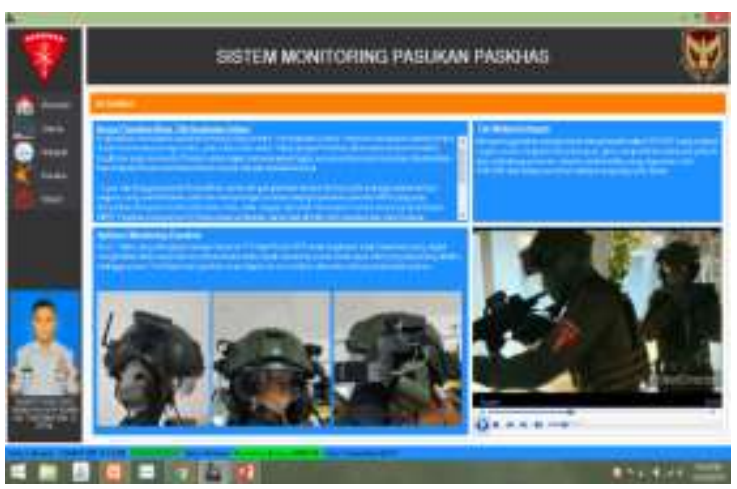

Figure 19 Home page

\section{c. Main page}

The Main Page in this application displays the location information in the form of a googlemap display with location markers for Team Matan (force markers) and Tactical Command Cars (marker rantis) which are equipped with Latitude and Longitude coordinates (Latitude, Longitude), Altitude, Heading Angle Tools that indicate the direction towards the user and the distance between the tool user and the tactical command post as well as a message column that can be used to send an operation command message which will later be read on the Micro OLED screen mounted on the tactical helmet. 


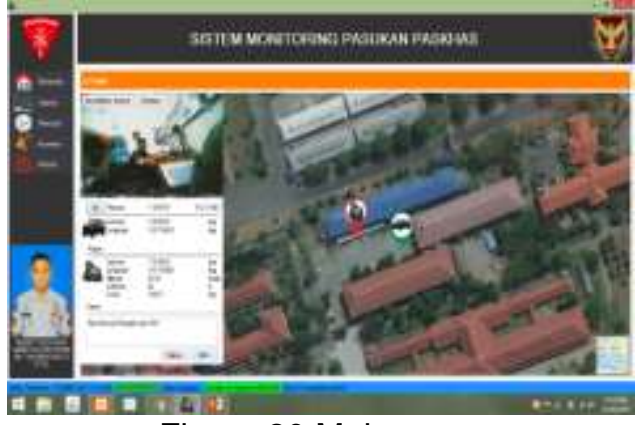

Figure 20 Main page

\section{d. History page}

On this page there are 3 columns that contain data stored data including message data sent, coordinate data and image recording data, so that the operator can view or play back the recording results when using this army monitoring application.

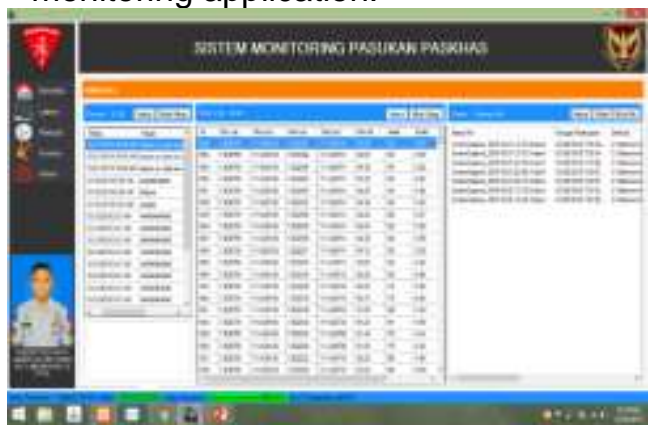

Figure 21 History page

\section{e. Connection page}

On this connection page contains information about the status of the telemetry connection with the GPS data serial display on the terminal in green, if there is no connection then the serial data will be worth 0 (number 0 ) and if there is a telemetry connection between the Transmitter unit and Ground Station Unit then the value in the data series will contain GPS data and time. To make a connection, the serial COM must be selected on the COM Port option, select the port that is connected, then press the Connect / Disconnect button.



Figure 22 Connection page

\subsection{Testing}

This test aims to determine the performance of each piece of equipment including the hardware used as a Transmitter Unit and the hardware used as a Ground Station Unit to function properly also to determine the output of each piece of equipment. The hardware testing side of the Transmitter Unit includes testing the TS100 GPS module, FPV Camera and AKK FX while the hardware testing of the Ground Station Unit side includes the 3DR Telemetry and VTX ROTG testing as well as the software used to run this troop monitoring application.

\subsubsection{Hardware Testing}

Hardware testing is carried out to determine the working capability of the equipment installed in the troop monitoring application system. Tests are carried out on the GPS sensor whether it is able to capture satellite signals properly in confined spaces and open spaces because it will determine the accuracy of the coordinates received, as well as the ability of the FPV camera to capture images in sufficient light and low light conditions, because this will affect the quality of recorded images .

Tests are also performed on the ground station unit in the form of a 3DR telemetry antenna and VTX antenna, where the maximum trasmit data range that can be received by the antenna will be known so that the software application can process the received data data into a display of information as expected.

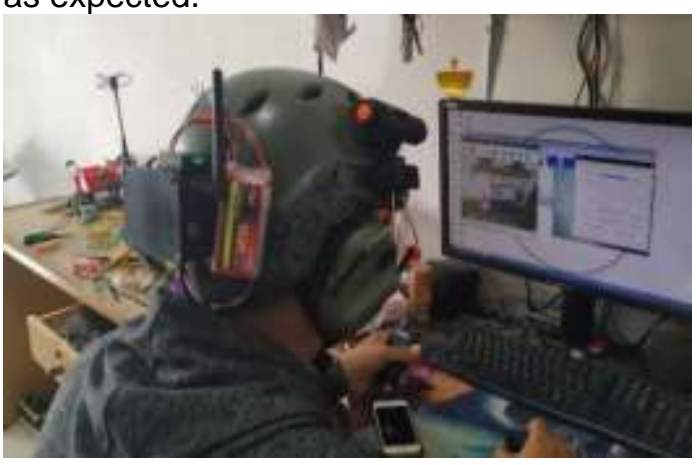

Figure 23 Testing tool

\subsubsection{Software Testing}

Software testing is the most important thing that aims to find out the design results that have been made and find errors / bugs in applications that are built in the execution process. The appearance of this application uses Visual Studio 2017 with the C \# program language, after each component on the application display page is created and loaded with the program according to the desired function then to test it then press the running 
button on the taskbar, it will appear some important information when the program is run. In this test, after finishing writing a sketch of the program in Arduino IDE with the $\mathrm{C}$ program language then uploading and saving, the next step is to run the program and to see the program execution can be checked by opening the serial monitor.



Figure 24 Testing of a visual studio program

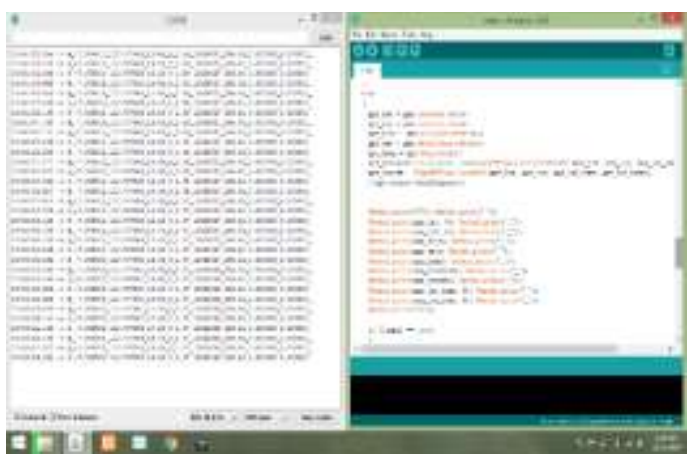

Figure 25 Testing the arduino program

After testing it will be seen whether the program is made as expected, if there are errors in writing the program there will be a warning in the error list column and the program will not be able to run as desired.

\subsubsection{Integrated Testing}

Testing the army monitoring system using online-based radio telemetry in an integrated manner can be carried out after all hardware and software components that support the system process have been completed and installed correctly, testing is done by attaching a tool to a tactical helmet that is used by the Matan Team as a transmitter unit and placing ground station unit in a Turangga tactical vehicle.

This test was carried out directly to the Battalion Command 463 Matanun Matanun Matan Team in a VVIP / VIP security simulation exercise in an open area and a hostage release exercise.

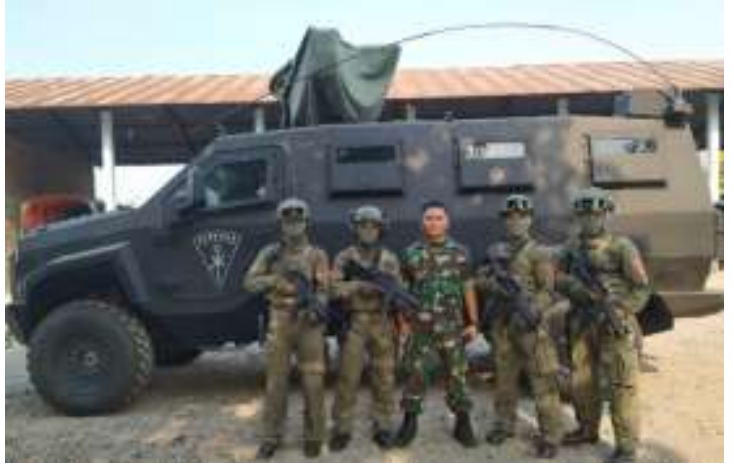

Figure 26 Tim Matan Yonko 463 Paskhas

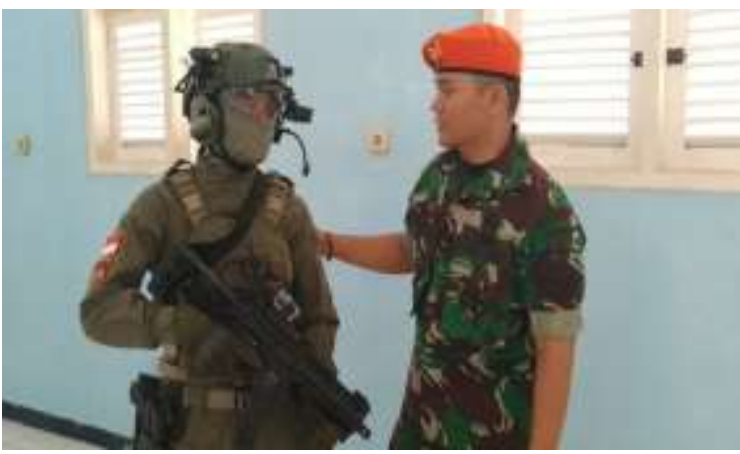

Figure 27 Matan's team wears a tactical monitoring helmet



Figure 28 Display on the OLED screen

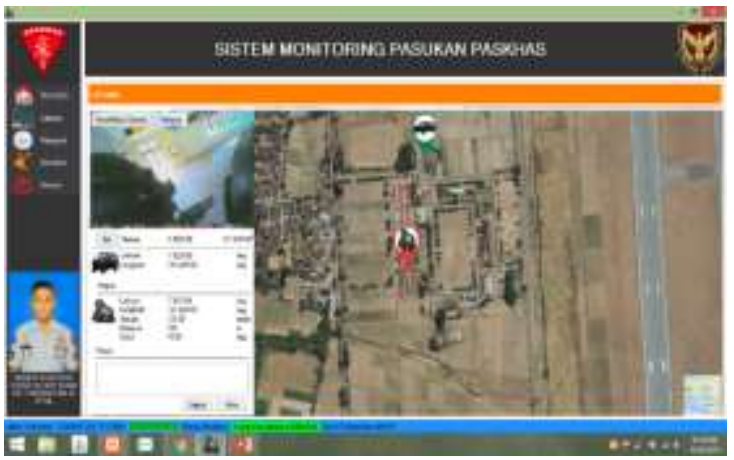

Figure 29 Views on the troops monitoring application 
Table 2 Results of testing in open areas

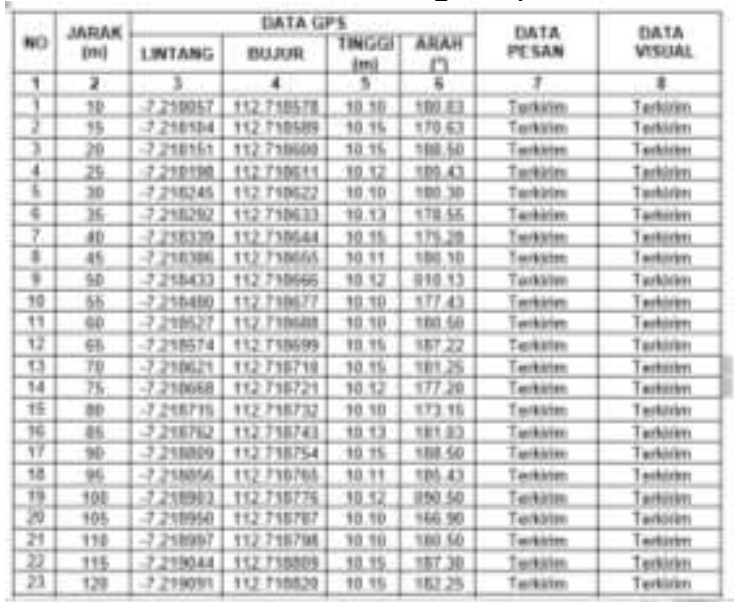

Table 3 Test results in closed area

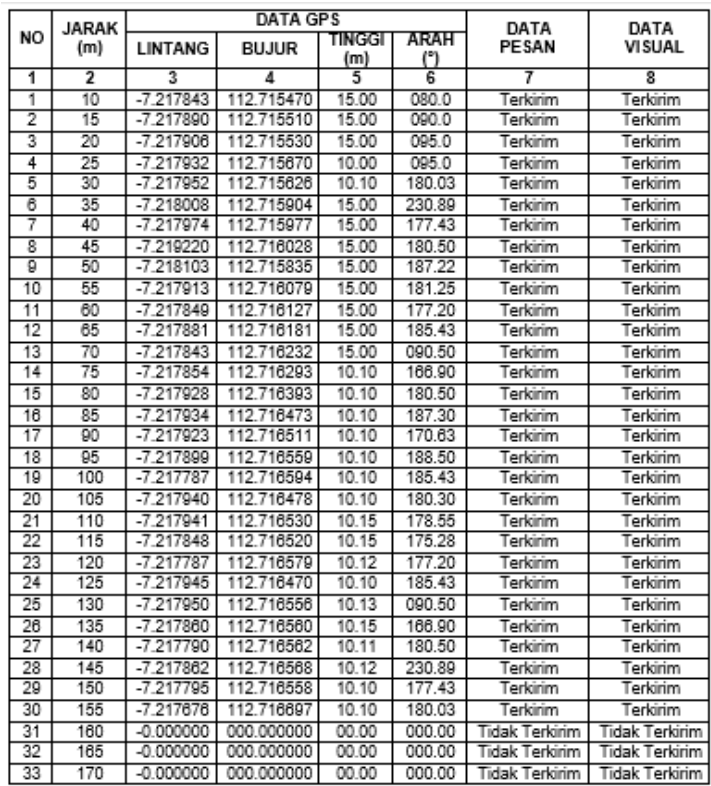

The test results listed in table 2 are tests conducted in an open area that is an area where there are no obstacles or obstacles that can inhibit the emission of telemetry frequency waves. The maximum distance between the transmitter unit to the ground station unit can reach +/- 250 meters for Telemetry signals and 490 meters for VTX signals.

Table 3 is the result of tests conducted in a closed area, namely in an indoor area where there is an obstacle in the form of a wall barrier / wall of a building, where the thickness and material of the wall / wall can inhibit telemetry waves and VTX signals transmitted so that the maximum distance between the transmitter unit and the ground station unit is only able to reach +/- 155 meters.

Measurement results in the form of heading data indicate the direction of the device with reference to the compass angle to the north pole of the earth where $0^{\circ}$ shows north, $90^{\circ}$ shows east, $180^{\circ}$ shows south and $270^{\circ}$ shows west while altitude data shows the position of the tool is measured from sea level in meters (masl).

\section{CONCLUSIONS AND RECOMENDATION 5.1 Conclusions}

The Design of Tactical Helmet Monitoring Forces Using the Online Based Telemetry System For the Pasatan National Command Battalion Matan Team can display information in the form of GPS data including Latitude Coordinates, Longitude Coordinates, Altitude, Altitude, Heading and Distance (Distance) displayed on the Gmap digital map and visual data in the form of audio video in MPEG format as well as short message data that can be read on the Micro OLED screen which is very useful in a series of monitoring and communication systems for the Matan Team in the field, Unit Commander at the command post tactical and Central Leaders who are in the Operations Command and Control Center (Puskodalops) when carrying out exercises or actual operations so that supervision and monitoring can be done in real time and can assist in making an important decision by the Commander / Leader in carrying out a faster, more precise operation and accurate according to dila conditions food and can be taken into consideration in evaluating the activities carried out.

\subsection{Recomendation}

Based on the results of trials on the Design of Tactical Helmet Monitoring Forces Using the Online Based Telemetry System For the Paskhas Command Battalion Matan Team, Recomendation can be given as follows:

a. To increase the telemetry range so that it can be further connected to a repeater antenna with the same frequency and use an I2C port system that can receive data from more than 2 device transmitters (Multilexing).

b. Micro OLED can be replaced with a more futuristic Transparant Micro OLED so that the information displayed will be more complete and clear.

c. For development, you can use an infrared-capable camera so that it can produce good images in low light or dark conditions.

d. To monitor the capacity of the battery used, you can add a battery indicator tool that can be displayed on the main page of the application so you can find out the battery capacity and the length of time the battery is used. 


\section{REFERENCES}

Arduino. (2018). Arduino NANO Rev3. Retrieved from https: // store arduino.cc/usa/arduino-nano-rev3.

Candra, D., Syahlan, Z., \& Widodo, E. (2019). DESIGN AND DEVELOPMENT OF THE MEASURING OF THE BODY MASS INDEX TO THE INDONESIA NAVY BASED ON VISUAL STUDIO. INTERNATIONAL JOURNAL OF ASRO - STTAL, 10(2), 116-124. Retrieved from http://asrojournal-

sttal.ac.id/index.php/ASRO/article/view/ 237

Kendall E Kenneth and Kendall E Julie. (2006). Systems Analysis and Design. Bandung: PT. Index.

Prof. Dr. Jogiyanto Hartono, A. M. (2009). Information Technology Systems-Edition III. Yogyakarta: Andi Publisher.

Sunyoto, Andi. (2013). GPS Data Processing System. AMIKOM STIMIK Journal. Yogyakarta.

Rozikin, C., Kurnianto, F., Ahmadi, A., \& Syaifi, M. (2018). DESIGN OF SHOOTING SCORE RECORDING INFORMATION SYSTEM BASED ON IMAGE PROCESSING. INTERNATIONAL JOURNAL OF ASRO - STTAL, 9(1), 136141. Retrieved from http://asrojournalsttal.ac.id/index.php/ASRO/article/view/ $\underline{239}$

Jaya, I., Maryanto, E., Bukit, A., \& Zulkifli, M. (2018). DESIGN AND DEVELOPMENT OF EARLY HEAT STROKE DETECTION SYSTEM IN MILITARY CROSS COUNTRY BASED ON IOT. INTERNATIONAL JOURNAL OF ASRO - STTAL, 9(2), 141-151. Retrieved from http://asrojournal-

sttal.ac.id/index.php/ASRO/article/view/ 241

Faturrochman, M., Suprayitno, S., Zulkifli, M., \& Widodo, E. (2019). DESIGN OF FUEL'S VOLUME MEASUREMENT MONITORING SYSTEM ON INDONESIAN NAVY FUEL TANK "SPBT" BASED ON THE Internet of Things (IOT). INTERNATIONAL JOURNAL OF ASRO - STTAL, 10(1), 112-116. Retrieved from http://asrojournal-
sttal.ac.id/index.php/ASRO/article/view/ $\underline{235}$

Wibisono, B., Bukit, A., Bandono, A., \& Widodo, E. (2019). DESIGN AND DEVELOPMENT OF MORSE LEARNING SYSTEM APPLICATION BASED ON VISUAL BASIC. INTERNATIONAL JOURNAL OF ASRO - STTAL, 10(1), 105-111. Retrieved from http://asrojournalsttal.ac.id/index.php/ASRO/article/view/ $\underline{234}$ 